\title{
THE ROLE OF GUIDANCE COUNSELLORS IN UNIVERSAL BASIC EDUCATION SCHOOL BASED ASSESSMENT
}

\author{
OKO, K. Azu (Rev.) PhD Mcasson \\ Consultant \\ Life Circle Counselling Centre \\ Aba, Abia state \\ email: life_circlecentre@yahoo.com
}

\begin{abstract}
This monograph on the role of guidance counsellors in School Based Assessment of Universal Basic Education explored the counselling features of the 6:3:3:4 curriculum such as multiple entry and exit phases, monitoring, functionalism and continuous assessment. It also explored the origin of the school based assessment; the difference between it and the current concept of continuous assessment and the functions of counsellors in the implementation of the school based assessment. The weaknesses of the previous UPE which failed to achieve its objective were highlighted to promote precautionary measures. The paper ended with recommendations on the necessary changes the government and counsellors can make to neutralize the impression that counselling is the same as advice giving and to realize the counselling objectives of the Universal Basic Education.
\end{abstract}

Key Words: Education, Counsellors, Assessment, Nigeria

\section{Introduction}

The teaching-learning process features dynamic persons who are subject to influences from several extraneous variables. They have a past which shaped their present; they are grappling with a present which is shaping their future and they have a future to look forward to which makes existence meaningful. The ability of the individual learner to harmonize his past, present and future facilitates learning and overall achievement in life, hence the need for the services of counsellors to facilitate the process of harmonization. Counselling draws upon the past of an individual and brings it to bear on the present of the same individual in order to fashion a future that ensures self-realization and selfactualization of such individual. This is only possible where you have 
appropriate and accurate data to analyze and interpret. The counsellor has a pronounced role to play both in the collation and interpretation of data in school based assessment especially in the affective and psychomotor domains. The following discussion is designed to highlight the indispensable role of the counsellor in this onerous task.

\section{The 6:3: 3: 4 Education System}

According to Okpala (1991) in Okonkwo (1998), the 6: 3: 3: 4 system of education launched in 1982 replaced the 6:5:4 system as a result of the recommendations of the 1969 national curriculum conference which featured experts from all field of life. A child, in the new system, spends six years in the primary school; three years in the junior secondary school; three years in the senior secondary school and four years in the tertiary institution. Basic education in the new system consists of the first nine years which covers primary and junior secondary education; a feature which has led many to describe it as the 9:3:4 system of education. In essence, the Universal Basic Education is not a new system of education but an implementation strategy of the 6:3:3:4 system of education to ensure that every Nigerian child benefits from the free basic education policy of the federal government. The Universal Basic Education is designed to facilitate the achievement of objectives of 6: 3:3:4 system of education. The 6:3:3:4 system has existed for over 27 years now (19822010) without achieving some of its objectives like skill acquisition for self employment; mass literacy, continuous assessment, enhanced academic standard in schools and value re-orientation. The implementation strategy features replacement of the common entrance with cumulative school based assessment as criterion for promotion to junior secondary schools; synthesis of the former primary school and junior secondary school curriculum into a nine years single curriculum and replacement of the first school leaving certificate with junior secondary school certificate . One of the reasons for preferring the 6:3:3:4 system to the 6:5:4 system of education was its rich program of guidance which is evident in the features depicted in Table 1.

It is interesting to note that most of the special features of the 6:3:3:4 curriculum fall under its program of guidance. Little wonder that the nation is finding it difficult to achieve most of the objectives of the 6:3:3:4 system in an environment where counselling is not enjoying prominence. The 6:3:3:4 system of education stands or falls with guidance (Onwuka, 1981). 
Table 1: Counselling Features of 6:3:3:4 Curriculum

\begin{tabular}{|ll|l|l|}
\hline \multicolumn{1}{|c|}{ Program of Guidance } & $\begin{array}{c}\text { Program of } \\
\text { Activities }\end{array}$ & $\begin{array}{c}\text { Program of } \\
\text { Studies }\end{array}$ \\
\hline 1. & multiple entry phases & & \\
\hline 2. & multiple exit phases & & \\
\hline 3. & functionalism & & \\
\hline $4 . \quad$ monitoring & & \\
\hline 5. & $\begin{array}{l}\text { school-based assessment (continuous } \\
\text { assessment) }\end{array}$ & & \\
\hline
\end{tabular}

Oko: 2003

\section{Multiple Entry Phase}

The system features a total of five entry phases including the nursery school. These are transition from home to nursery school; entrance into primary school; entrance into junior secondary; entrance into senior secondary and matriculation into the tertiary institution.

Counselling activities at these phases centre on the following: identification of interest, motivation for learning, ascertaining of intelligence quotient and learning disorders, identification of needs and aspirations of each student, familiarization with school culture cum environment which is popularly known as orientation and transfer of attachment from home to school, etc.

\section{Multiple Exit Phases}

There are five exit phases including nursery school. These are graduation from nursery to primary; primary to junior secondary and junior secondary to senior secondary or trade centre. Others are graduation from senior secondary to university or trade centre/employment and graduation from university to respective careers. Counselling activities at these phases are based on cumulative information on students' ability, aptitude, interests, skills and home background. The information helps to decide

(1) type of institution to continue education in future,

(2) appropriate vocations in the world of work,

(3) how to secure and maintain a job, and

(4) alternative forms of schooling e.g. non-formal, adult, evening, etc. 


\section{Functionalism}

Functionalism lays emphasis on transformation of innate potentials/talents to skills, competences and abilities for self sustenance to enable one live meaningful and fulfilling life. The acquired skills should tally with one's personality variables and could easily be translated to self-employment. This calls for a well articulated vocational guidance.

\section{Monitoring}

The monitoring component of the system embraces observation and participation in the teaching/learning process of the school. Some problems of students stem from interaction with their home or school environment. The causes of the problems are external and as such the student who often is unaware of the innate causes of his behaviours may not be able to reveal this in any inventory. A student who is having difficulty with a particular subject may be suffering from projection. He is transferring his hatred for the teacher to the subjects the teacher teaches. A close observation of the flow of interaction in such classroom may reveal this to the counsellor.

Similarly a teacher who complains of harassment or stubbornness of students may be battling with displaced aggression. He may not be aware of the fact that he initiates the aggressive response of the students by his own behaviour. Aggression provokes aggression. The counsellor can be of help in such situation after monitoring the class and analyzing the psychological roots of the problem. Most classroom problems are reactions of students to stimuli which they considered unacceptable. The monitoring function concentrates on the following areas of importance: (1.) student versus teacher interaction; (2.) student versus student interaction; (3.) student versus material interaction (4.) teacher versus material interaction (5.) student versus environment interaction (6.) student versus examination interaction (7.) deviant behaviours (8.) special talents (9.) follow-up of ex-students and individual cases of referral.

\section{School based assessment (SBA)}

School based assessment is not different from the correct concept of continuous assessment. They have the same scope, the same characteristics and use the same instruments and personnel.

\section{School Based Assessment}

The misunderstanding of continuous assessment has been so deeply ingrained in the school system that it is reasonable to use the alternative 
terminology which is SBA. In this discussion SBA will be used to describe the right concept of continuous assessment while continuous assessment (CA) will be used to refer to its misconstrued meaning.

Continuous assessment has been misconceived as periodic examination of the cognitive ability of students. The sum total of such tests are computed as $40 \%$ continuous assessment score and added to the $60 \%$ final examination score to derive the grade. It is noteworthy that the weekly tests and final examinations derive from the module topics which fall under program of studies and are strictly cognitive. Thus the current practice can best be described as cognitive continuous assessment. Although objectives are specified in the three domains of learning, testing concentrates only on the cognitive. The rating scale for the variables in the affective and psychomotor domains is neither interpreted nor transformed into a score for the purpose of computing the final grade of a student. The psychomotor and affective do not constitute part of the grade. Annual and trimester results are still treated in isolation without any significance attached to the cumulative grade. The grade of a student in a class is still determined by adding his score in the periodic cognitive tests popularly known as continuous assessment which constitute $40 \%$ and his score to the trimester final examination which constitute $60 \%$ (Akanwa:2004). Cross-examination of score columns in the current primary and secondary report cards confirms this.

\section{Origin of School based assessment}

National Policy on Education (2004) prescribed that "educational assessment and evaluation shall be liberalized by their being based in whole or in part on continuous assessment of the progress of the individual". The continuous assessment hereby referred to as Student Behaviour Assessment emanated from a synthesis of the British onceand-for-all assessment prevalent at University of Ibadan and the progressive assessment built into the teaching-learning process without final examination at University of Nigeria Nsukka (Nwana, 1997). 


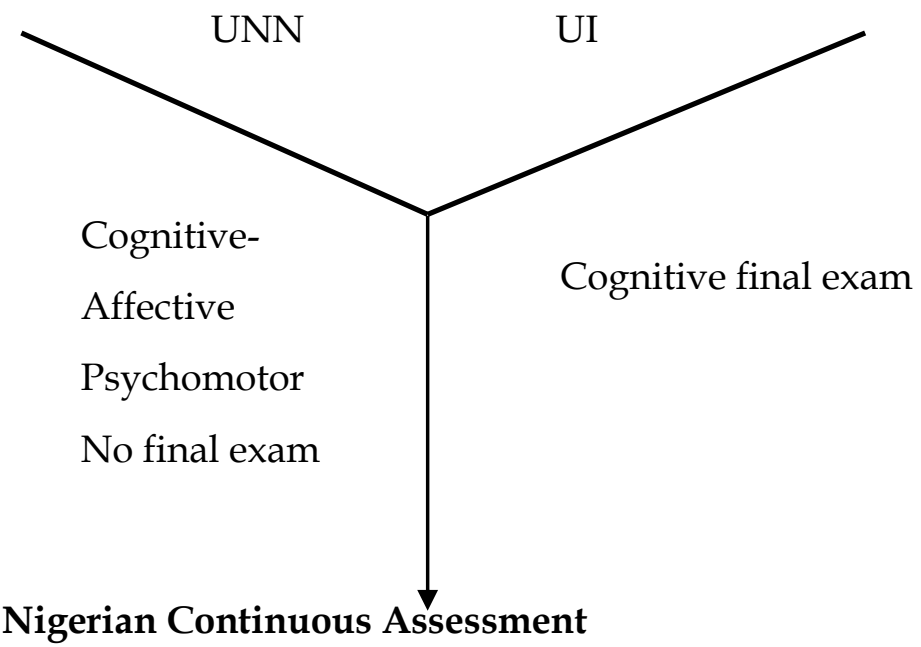

\begin{tabular}{|c|c|c|}
\hline Affective $20 \%$ & Psychomotor $20 \%$ & Cognitive $60 \%$ \\
\hline $\begin{array}{l}\quad \text { Components } \\
\text { Punctuality } \\
\text { Neatness } \\
\text { Cooperation } \\
\text { Leadership } \\
\text { Hygiene } \\
\text { Emotional stability } \\
\text { Attentiveness } \\
\text { Politeness } \\
\text { Altruism } \\
\text { Perseverance } \\
\text { Health } \\
\end{array}$ & $\begin{array}{l}\quad \text { Components } \\
\text { Handwriting } \\
\text { Verbal fluency } \\
\text { Games/sports } \\
\text { physical education } \\
\text { handling tools } \\
\text { drawing/ painting } \\
\text { musical skills } \\
\text { laboratory Practical } \\
\text { class attendance }\end{array}$ & Components \\
\hline Assessment Strategies & Assessment Strategies & Assessment Strategies \\
\hline $\begin{array}{l}\text { Logs / diaries } \\
\text { Personal diaries } \\
\text { Report from parents } \\
\text { Anecdotal records } \\
\text { Complains } \\
\text { Interviews } \\
\text { Class sociogram } \\
\text { Questionnaires }\end{array}$ & $\begin{array}{l}\text { Observation schedules } \\
\text { Checklists } \\
\text { Interviews } \\
\text { Attendance Register } \\
\text { Projects } \\
\text { rating scale } \\
\text { Occasional Report } \\
\text { Etc. }\end{array}$ & $\begin{array}{l}\text { periodic test (formative) } \\
\text { Assignments } \\
\text { Final examination } \\
\text { Quizzes }\end{array}$ \\
\hline
\end{tabular}

According to Federal Ministry of Education (1985), school based assessment may be viewed as a method of finding out what a pupil has 
gained from learning activities in terms of knowledge, thinking and reasoning, character development and industry. Bajah (1984) in Akanwa (2004) described it as more valid form of assessment that samples a much wider range of skills and abilities inherent in a course of study. This means that beside paper and pencil tests, a student's overall grade in each course is derived from such variables as his skill in handling tools, materials, equipment and behaviour such as attendance, participation in class work and assignment.

Okpala (1993) defined it as a system of assessment which is carried out at predetermined intervals for the purpose monitoring and improving overall performance of students and of the teaching learning environment. Its purpose is to assess the totality of the learner. Teachers are expected to asses the performance of the students in the cognitive domain, observe and rate their attitude to work, group relations, laboratory behaviour, motivation, ability to manipulate equipments, observe procedures, make measurements etc. For primary and secondary schools it is suggested that assessment of non-cognitive behaviours could be done through rating scales with a key to explain the scale. The data generated from the scale is converted to a grade. The performances of the child in the three domains are combined to obtain a single index of performance for that term. Promotion is to be based on the cumulative grade of the child which is derived by computing the average of all the terms/years he has spent in the school system. The state school system has been practicing continuous assessment limited to the cognitive domain but the UBE policy demands that student behaviour assessment spread across the three domains of learning (Uyoata \& Nzotta , 1996).

Comparison of SBA and Current CA

\begin{tabular}{|ll|ll|}
\hline \multicolumn{2}{|c|}{ SBA } & \multicolumn{2}{c|}{ CA } \\
\hline Cognitive summative & $40 \%$ & Cognitive summative & $60 \%$ \\
\hline Cognitive periodic tests & $20 \%$ & Cognitive periodic test & $40 \%$ \\
\hline Psychomotor assessment & $20 \%$ & Psychomotor assessment & ----- \\
\hline Affective assessment & $20 \%$ & Affective assessment & ------ \\
\hline Grade & $\mathbf{1 0 0} \%$ & Grade & $\mathbf{1 0 0} \%$ \\
\hline
\end{tabular}

The Cumulative School based assessment(CSBA) which covers what the pupil has done from primary one to primary six (eighteen trimesters) in the three domains of learning provides the grades for certification, promotion and placement of primary six pupils in Junior secondary schools. In the case of Junior secondary students, the CSBA 
which covers what the student has done from primary one to primary nine (27 trimesters) in the three domains of learning provide the grades for certification and promotion of Junior Secondary School students. CSBA provides wider and more valid information on the subjects. This explains the rationale behind the proscription of common entrance and first school leaving certificate examinations. The examinations are parochial assessments being based only on the cognitive domain. Certification of primary six pupils as well as their selection for junior secondary should be based on the cumulative student behaviour assessment.

\section{Functions of Counsellors in School Based Assessment}

1. Provision/construction of non-cognitive instruments for teachers to use in evaluating the affective and psychomotor domains.

2. Analysis and interpretation of data gathered with such instruments.

3. Construction of SBA blue print for the term.

The guidance counsellor should produce the SBA blue print for each term with the following specifications:

(a) Number of assessment scheduled for the term

(b) Topics of modules in which assessment is to be based.

(c) The objective domains to be assessed.

(d) Types of instrument to be used

It is the duty of the teacher or subject head teacher to produce a test blue print for the module topics in the term.

4. Analysis of cognitive domain test result to ascertain the following:

(a) Correction for guessing

(b) Item Difficulty

(c) Discriminating index

(d) Effectiveness of distracters

(e) Skewness

5. Vetting of scores awarded by teachers in the psychomotor and affective domain based on insights from data generated in monitoring exercise.

\section{Universal Primary Education in Retrospect.}

The UBE is an expression of the strong desire of the government to reinforce participatory democracy in Nigeria by raising the level of awareness and general education of the entire citizenry (Adeyanju 2001). In the light of this, there is need for caution to avoid making the same mistakes that made Universal Primary Education (UPE) which was 
launched in 1976 for similar reasons to fail. The writer wishes to draw a line of demarcation between failure of UPE and its termination. The UPE was terminated in 1982 due to diversion of fund by some state government who saw the UPE funds allocated to them as their share of the national cake. Although the UPE was terminated for political reasons, it failed to achieve its academic objectives for the six years it lasted due to the following reasons (Okonkwo, 1998):

\section{Recruitment of teachers without aptitude test}

The mass teacher recruitment exercise of UPE witnessed many market women, farmers, and carpenters etc. who abandoned their occupation for teaching appointments. Most of them were not the right materials for academic work but they joined the teaching profession for fiscal motives due to the Udorji award for civil servants which coincided with it. They acquired the necessary qualifications through the various crash teacher training programs that accompanied the exercise. Many of them later abandoned the work and returned to their previous vocation while those that managed to remain abused the profession by using school hours for commercial or horticultural ventures. Possession of a Nigerian Certificate of Education does not make someone an efficient and effective teacher automatically. The application of relevant psychological instruments will help to recruit the best candidates and forestall the sad experience of UPE which weighs heavily on the pupils.

\section{High dropout rate due to academic and socio-personal problems.}

The UPE program was characterized by the absence of well articulated guidance program in the schools which resulted to high dropout rate due to discouragement despite the automatic promotions that featured in the exercise. Nwaine (2005) observed that low quality of work increases the chances of failing. Failure retards the progress of the child through discouragement, inferiority complex and poor grades. Inferiority complex, poor grades and discouragement result in dropping out since children, like adults, do not take active and sustained interest in tasks at which they continually fail. A strong educational counselling program must be initiated to avoid a reoccurrence. This is of crucial importance in view of the male-drop-out-syndrome already prevalent in the environment. 
Population explosion in the labour market without commensurate vacancies.

Colonial mentality has conditioned Nigerians to associate education with the white man's job opportunities. Just as it happened during the UPE, most of the children being registered today will go beyond the basic education and graduate to join the world of labour. The UPE contributed immensely to high unemployment rate in the country today due to the inability of the products to translate learning to meaningful self employment.

The intelligent ones who passed out without being gainfully employed by government became confused and maladjusted. Some of the current 419 fraudsters marring the image of the nation are products of that era. A strong vocational guidance program is necessary to avoid a repetition of the same mistake. One of the objectives of the UBE is to equip learners with knowledge, skills and attitude for self-sustenance. It takes counselling to make education functional.

\section{High rate of Indiscipline due to population explosion of pupils.}

The school population explosion created disciplinary and adjustment problems beyond the ability of teachers to handle. In the absence of a strong guidance program, children with deviant behaviour and other forms of indiscipline were abandoned to their fate in view of the fact that the exercise coincided with the withdrawal of schools from missions and proscription of religious instruction in schools. This resulted in saturation of the school with amoral, immoral and poorly cultured pupils. We cannot afford to make the same mistake again. It is interesting to note that some of the staff who are bad eggs in the government employment today had their basic education during the UPE.

\section{Non utilization of summative and cumulative assessment feedback}

Assessment results were not analyzed and interpreted in the light of children's individual needs and progress in order to integrate the result in the formulation of developmentally appropriate experience for the child due to the absence of counsellors. The teachers, with their overcrowded class, were too busy to pay attention to children with unique learning problems. In the end UPE achieved literacy but not education of pupils. Quality education was sacrificed for quantity. The UPE produced half-baked students and we know the impact on our nation and the education industry today. 


\section{Recommendations}

Uphold provisions of the NPE on promotion and certification of primary six pupils.

The provisions of National Policy on Education that certification and promotion of primary six pupils be based on cumulative School Based Assessment instead of the first school leaving examination should be upheld. The continuation of these examinations in the state creates the impression of a state that is not in tune with current developments in the educational sector. The CSBA which covers what the pupil has done from primary 1-6 (eighteen trimesters) in the three domains of learning provides the grades for certification, promotion and placement of primary six pupils in junior secondary schools. In the case of Junior secondary students, the CSBA which covers what the student has done from primary 1-9 (27 trimesters) in the three domains of learning provide the grades for certification and promotion of Junior Secondary School students. CSBA provides wider and more valid information on the subjects.

If a uniform test must be taken to ensure standard, such test may not attract more than $40 \%$ of the total marks awarded to the cognitive domain of SBA, thereby leaving $20 \%$ for CSBA in the same domain. The pupils' grade may be composed of the following score distribution: cognitive final exam $40 \%$; cognitive CSBA $20 \%$; psychomotor CSBA $20 \%$ and affective CSBA $20 \%$.

Restructure the Examination development centre of the Ministry of Education

The Examination Development Centre (EDC) should be restructured to reflect realities of UBE. Its primary function in UBE is collation of cumulative annual data from schools; preservation and analysis of same for decision making in cases of pupils' transfer; promotion to junior secondary; first school leaving certification; Junior secondary certification and computation of the $30 \%$ continuous assessment (i.e. now CSBA) required for the SSCE certification. Head teachers and principals are no longer required to provide the so called $40 \%$ or $30 \%$ continuous assessment score to the ministry of education or WAEC respectively. The EDC has the cumulative data on every child in the school system to provide that.

In addition, the centre is to ensure standard by correlation of WAEC result of SSCE students from the state with their CSBA before such results are released to the schools by WAEC. Cases of zero or very low 
correlation coefficient should be investigated as suspected cases of examination malpractice or revalidated through a sample follow-up equivalent examination to be administered by the centre. The SSCE result of those convicted should be withheld through WAEC. The centre is also to assist the tertiary institutions in the state to maintain standard by correlating JAMB results with the students' CSBA. Only candidates whose JAMB score correlates positively with their CSBA should be admitted into the state tertiary institutions. This will bring examination malpractice to the barest minimum and check the activities of the special centres which have ruined our secondary school system. It will also make the post JAMB aptitude examination, which has been characterized by malpractice and extortion in our universities, unnecessary. In addition, the name of EDC could be changed to Student Behaviour Assessment Centre (SBAC). A post graduate guidance counsellor should be appointed to direct the centre with the assistance of a psychologist or someone who read measurement and evaluation. This will facilitate interpretation of data and drawing of accurate conclusion or inferences for decision making.

\section{Check illegal examination fees}

The current first school leaving, common entrance and junior secondary school examination registration fees should be proscribed. They create the impression of a state that is characterized by official extortion. UBE is meant to be free education up to the tune of feeding in schools. In their place the Ministry of Education can stipulate a fee for the cumulative school based assessment exercise at each of the levels. The fee may be called CSBA fee and could be paid directly to the SBAC account to forestall hijacking of the fund. The work of the SBAC is so vital to the success of the UBE that funds should not be allowed to ground it. It needs a source of internal revenue directly under its control in addition to the statutory fiscal allocation due to it.

\section{Provision of Fund for in-service training of counsellors}

Funds should be provided for the state branch of the Counselling Association of Nigeria (CASSON) to embark on capacity training workshops for counsellors on acquisition, production, analysis and interpretation of psychological instruments such as rating scales, inventories, etc. These tests are compulsory requirements in SBA. 


\section{Provide suitable report card}

The state school system needs a UBE report card that will reflect the realities of the School Based Assessment. The current report card lacks many columns required in SBA.

\section{Apply psychological tests in recruitment of teachers}

The current UBE teachers' recruitment exercise in the state should feature aptitude tests and vocational interest inventories to be sure that the right people are selected.

\section{Professionalize counselling in schools}

Counsellors should be relieved of teaching appointments and provided with office space and logistics to play their role in the UBE program. The poor attitude to counselling among students and administrators in Abia State is corroborated by the following apparent facts:

1. poor funding of counselling in schools

2. lack of directives to principals on the role of counselling in the 93-4 education system.

3. lack of office equipment and materials for counselling

4. transfer of traditional counselling functions to other teachers in the school by principals, etc.

Examination of the above fact shows that they are effects and not causes of the problem; a stimulus prompted the negative attitude of principals, teachers, policy makers and students. The tendency to bring others to the bar in problem situations is natural and satisfactory to our ego; but the facts remain that it is often best to begin with ourselves. Is it possible that the behavioural scientists are becoming victims of the behavioural vices they have been trained to control? Could it be that we have allowed the defence mechanism of projection to cloud our reason and initiative? It is not true that everyone out there is responsible for the decline in counselling activities except the counsellors.

I wish to reiterate that Guidance/Counselling did not find its way into the national policy on education by resolution or communiqué to the government but by achievement and merit. It was the extraordinary feat achieved by Rev. Sisters at St. Theresa's College Ibadan that attracted the attention of the Federal Ministry of Education and triggered events that resulted in official policy statement on counselling. The same is required today. Denga (1998) noted that the government has mobilized counsellors running into thousands into the school system. Despite this, the school is besieged and inundated with various categories of educational 
malpractices such as cultism, truancy, poor performance, violence, students with wrong career choices and other personality problems. The populace is raising eyebrows regarding the relevance of the counselling discipline. The threat to revert counsellors to classroom teaching has been looming and it is clear that only productivity can neutralize that threat (Odoemelam: 1999). The silence of counsellors to government's cry of despair during the Wilcox and Boy's High School rioting and vandalizing of property saga in Aba is very ominous. The behavioural experts shrank from their duty and allowed the government, out of despair, to take the unfair primitive decision of shutting down the schools. CASSON should provide solution to such problems in the state if it is worth its salt and thereby carve a niche for itself in the heart of government. Do you respect, recognize and give monetary support to a police officer who goes to sleep when the armed robbers are operating in his environment?

We have betrayed the dignity of the profession by resorting to advice giving instead of counselling. A counsellor working without instruments is not different from the English or Biology teacher in the eyes of the public for anyone can advise. That is the major cause of the disregard for counsellors and their practice as well as the denial of fiscal support. We have failed to distinguish ourselves from the road side advice giver through the application of psychological tests in our practice. Nkwocha (1997) notes that some people ignorantly limit the scope of the word test to classroom work. A test is any standard, instrument or strategy used to determine the existence or non-existence of attributes in an object or person. Psychological tests are scientific tools or exercises used to elicit a sample of behaviour for analysis and generalization (Ugwuegbulam: 1997). Can you imagine a medical doctor prescribing drugs for you with out applying any instrument or test? Even when they know the symptoms, they apply the instruments as a matter of professional ethics to make their practice more credible. It is the use of instruments that distinguishes you from the lay counsellor. Counselling without instrument reinforces the erroneous concept that counselling is same as advice giving which makes you dispensable. The instrument need not be a standard test or inventory, it could be an improvised checklist or idea presented in a professional way. The following table contrasts guidance and counselling with advice to show the difference. 
Table 1: Counselling Contrasted with Advice

\begin{tabular}{|l|l|}
\hline \multicolumn{1}{|c|}{ Guidance/Counselling } & \multicolumn{1}{c|}{ Advice } \\
\hline $\begin{array}{l}\text { Self reliance/self confidence } \\
\text { Equalitarian } \\
\text { Effective listening skills(prompts, } \\
\text { clarification; verbal and non- } \\
\text { verbal) }\end{array}$ & $\begin{array}{l}\text { Dependency syndrome } \\
\text { Superiority Complex }\end{array}$ \\
Specific and individualistic & Poor listening skill \\
Authoritative & Generalization/sweeping \\
Empirical & statements \\
Diagnostic & Authoritarian \\
Professional skills/knowledge & Subjective \\
\hline
\end{tabular}

Ekennia: 1998

\section{Summary}

The Universal Basic Education is designed to facilitate the achievement of objectives of 6: 3:3:4 system of education. The 6:3:3:4 system of education stands or falls with guidance. It is therefore imperative that the counsellors brace up the challenge of seeing that the U.B.E. did not suffer the same fate that U.P.E. suffered. This could be achieved by sticking to the provisions of the National Policy of Education instead of tradition professionalization of counselling in practice.

\section{References}

Akanwa, U. N. (2004) Evaluation of Continuous Assessment practices In Nigerian University in Onofeghara, N. (ed) (2004) Current issues in Nigerian Education: Enugu: chi-zo press Ltd

Denga, D.I..(1998) Educational malpractice and cultism in Nigeria. Calabar: Rapid educational publishers limited

Denga, D.I..( (2004) National Policy on Education. Yaba, Lagos: NERDC Press.

Ekennia C.C. (ed.) (1998) Essentials of Counselling. Owerri: Barloz publishers Nkwocha, P.C. in Elements of counselling practicum ed Ugwuegbulam C.N. (1997) Owerri: Caun publisher Nig Ltd

Nwaine, H.L. (2005) Factors Militating against the Implementation of Universal Basic Primary Education: A case study of Aba South L.G.A. Abia State. IMSU B.Ed Project. 
Nwanna, O.C. (1997) Advanced Research Methods. Abia State University, Uturu: Lecture Notes

Odoemelam, M.A. (1999) Organization and Administration of a Comprehensive Guidance and Counselling Programme for Schools. Owerri: Alphabet Nigeria Publishers.

Okonkwo, C.E.; Uruakpa, J.A.; Agada, J.C.; Kanu, O.R.(1991) History of Education. Imo state: Grace of God press

Okpala, P.N; Onocha, C.O.; Oyedeji, O.A. (1993) Measurement and Evaluation in education. Edo state: Stirling. Harden Publisher (Nig) Ltd.

Onofeghara, N. (ed) (2004).Current issues in Nigerian Education: A book of Readings. Enugu: Chi-zo Press Limited.

Onwuka, U. (1981) Curriculum Development for Africa. Onitsha: Africana. Fep publisher Ltd

Okonkwo, C. (1998) Comparative Education \& Educational Decisionmaking. Owerri: International Universities press Ltd

Oko, A. K. (2003) Introduction to Guidance and Counselling. Imo State University: lecture notes.

Ugwuegbulam, C.N. (ed) (1997) Elements of counselling practicum. Owerri: chin and chis ventures.

Uyoata, U.E \& Nzotta, E.N. (1996) “Assessment of learning Activities: A challenges for curriculum Development in early childhood Education" in The Researcher, 1:165-73 